\title{
Population Structure and Genetic Diversity of Fungi Causing Rice Seedling Blight in Northeast China Based on Microsatellite Markers
}

\author{
J. X. Liu, ${ }^{1}$ Y. N. Cai, ${ }^{1}$ W. Y. Jiang, ${ }^{1}$ Y. G. Li, ${ }^{1, \dagger}$ Q. F. Zhang, ${ }^{2}$ and H. Y. Pan ${ }^{3}$ \\ ${ }^{1}$ Agricultural College, Northeast Agricultural University, Harbin 150030, People's Republic of China \\ ${ }^{2}$ Heilongjiang Plant Quarantine and Plant Protection Station, Harbin 150036, People's Republic of China \\ ${ }^{3}$ College of Plant Sciences, Jilin University, Changchun 150000, People's Republic of China
}

\begin{abstract}
Rice seedling blight, which is caused by diverse pathogenic microorganisms, occurs worldwide and is the most important seedling disease affecting rice production in Northeast China. To further characterize the population structure and genetic diversity of the fungi responsible for rice seedling blight in Northeast China, 225 fungal strains were isolated from diseased rice seedlings collected from various rice-producing areas. The isolated strains included Fusarium oxysporum $(48.0 \%)$, F. verticillioides $(11.6 \%), F$. tricinctum $(8.0 \%), F$. redolens $(6.7 \%), F$. equiseti $(6.2 \%), F$. solani $(6.2 \%)$, Rhizoctonia solani $(6.7 \%)$, Alternaria alternata $(4.0 \%)$, and Curvularia coatesiae (2.7\%). F. oxysporum was the dominant fungal species causing rice seedling blight, with most isolates exhibiting moder-

sensitive to $10 \mu \mathrm{g} / \mathrm{ml}$ of carbendazim, implying that carbendazim is ineffective for controlling rice seedling blight in Northeast China. The $F$. oxysporum isolates were divided into nine groups based on a simple sequence repeat analysis involving 14 primer pairs. In addition, an analysis of molecular variance revealed a significant correlation between the $F$. oxysporum population and geographical location, which had a significant effect on the differentiation of the dominant isolate population. The results of this study provide insights into the genetic diversity of $F$. oxysporum strains causing rice seedling blight and may be useful for selecting isolates to screen for disease-resistant rice varieties, evaluating fungicide efficacy, and developing effective disease management strategies.
\end{abstract} ate pathogenicity. Moreover, to our knowledge, this is the first study to identify A. alternata and $C$. coatesiae as causal agents of rice seedling blight in Northeast China. None of the $F$. oxysporum isolates were
Keywords: Fusarium oxysporum, genetic diversity, population structure, rice, seedling blight
Rice is one of the most important and commonly cultivated cereal crops because it is a major staple food worldwide (Majumder and Banik 2019; Veerappan et al. 2019). Heilongjiang Province is one of the major rice-producing regions in Northeast China. Rice seedling blight is a serious disease and represents an emerging threat to global rice production. In China, the incidence of this disease has been increasing every year ( $\mathrm{Li}$ et al. 2016). The breeding of diseaseresistant rice varieties represents the most economical and efficient way to control diseases (Wei et al. 2014). However, there are relatively few reports describing research regarding the rice resources resistant to seedling blight. The application of chemicals remains the most effective way to control rice diseases. However, this is relatively ineffective for protecting plants from seedling blight, mainly because the pathogens responsible for rice seedling blight are complex and vary depending on the location (Dossou and Silue 2018; Riera-Ruiz et al. 2018). This disease is caused by several pathogenic microorganisms, including Fusarium spp., Pythium spp., Rhizopus spp., Curvularia lunata, Burkholderia glumae, B. plantarii, and Trichoderma spp. (Aye et al. 2008; Rush 1977; Wang et al. 2016; Whithey 1982; Yoneyama et al. 1998). Moreover, preventing and minimizing the adverse effects

${ }^{\dagger}$ Corresponding author: Y. G. Li; neaulyg@126.com

J. X. Liu and Y. N. Cai contributed equally to this work and are considered co-first authors.

Funding: This study was funded by the National Key R\&D Program of China (grant 2018YFD0201005), the National Natural Science Foundation of China (31971760), the Heilongjiang Collaborative Innovation and Extension System of Modern Agricultural Industry Technology of Forage and Feed, and the Major Projects of Research and Development Program of Application Technology of Heilongjiang Province of China (grant GA17B001).

The author(s) declare no conflict of interest.

Accepted for publication 13 September 2019

(C) 2020 The American Phytopathological Society of rice seedling blight remains difficult (Spence et al. 2014). Therefore, identifying the pathogens causing rice seedling blight and monitoring the incidence of this disease are important for developing effective disease control measures (Gao et al. 2001).

In an agroecosystem, the population structure and genetic diversity of pathogens may be affected by several factors, including the host range, environmental conditions, and application of fungicides (Huzar-Novakowiski and Dorrance 2018). To our knowledge, there is a lack of investigations and reports on the population structure and genetic diversity of the fungal pathogens responsible for rice seedling blight. However, information regarding pathogen genetic structures is crucial for developing effective disease management strategies (Hiremani and Dubey 2019; Pouralibaba et al. 2019). Simple sequence repeat (SSR) markers have diverse uses, including for analyses of the genetics of pathogenic fungi and population variability as well as for identifying pathogens (Ivors et al. 2006; Lees et al. 2006). For example, SSR markers have been applied to investigate $F$. oxysporum Schlecht. emend. Snyder \& Hansen regarding its ability to cause vascular wilt in lentil (Pouralibaba et al. 2019), Fusarium wilt in common bean (Cruz et al. 2018), and vascular wilt in guava (Mishra et al. 2013). However, the genetic diversity enabling $F$. oxysporum strains to infect rice to cause seedling blight remains relatively uncharacterized.

Rice seedling blight has not been effectively controlled. The objectives of this study were to identify and analyze the fungal species that cause rice seedling blight and to investigate the genetic diversity of the dominant strain. The relevant information presented herein may help researchers develop viable disease control strategies and breed disease-resistant varieties.

\section{Materials and Methods}

Isolation and identification of pathogenic fungi. A published tissue isolation method ( $\mathrm{Li}$ et al. 2019a) was used to collect fungal isolates causing rice seedling blight from 16 locations in 10 prefecture-level cities (Fig. 1) in Heilongjiang Province, China, in April and May 2018. Seedling blight symptoms, including withered tips, chlorosis, stunting, yellow leaves, leaf drop, crown rot, and inhibited root growth, were observed on rice plants. Fungal cultures 
were isolated from diseased tissues and grown on potato dextrose agar (PDA) at $25^{\circ} \mathrm{C}$ for 4 days.

The submerged-roots method in pots (Wang et al. 2019) was used to assess the pathogenicity of all isolates according to Koch's postulates. Dominant strains were selected for single-spore isolation via the spore dilution method (Zhao et al. 2001). Pathogenic isolates were mainly identified based on morphological characteristics (Booth 1971; Nelson et al. 1983) and molecular identification. To select representative isolates, the internal transcribed spacer (ITS) region was amplified by PCR with a fungal rDNA ITS primer pair (ITS1 and ITS4) (White et al. 1990). The PCR products were purified and sequenced by Shanghai Biological Engineering Co., Ltd. (Shanghai, China).

Determination of pathogenicity. The submerged-roots method (Wang et al. 2019) was used to evaluate the pathogenicity of 74 single-spore isolates of $F$. oxysporum derived from 16 locations in Heilongjiang Province. Specifically, the roots of six 15-day-old rice seedlings (cultivar Longdao 18) were submerged for $10 \mathrm{~min}$ in a suspension containing $10^{6}$ conidia/ml (Li et al. 2019a). The treated seedlings were then sown in pots, with five seedlings per pot and three replicates. Seedlings soaked in sterilized water served as controls. All of the inoculated seedlings exhibited symptoms that were identical to those observed in pots at 20 days after inoculation.

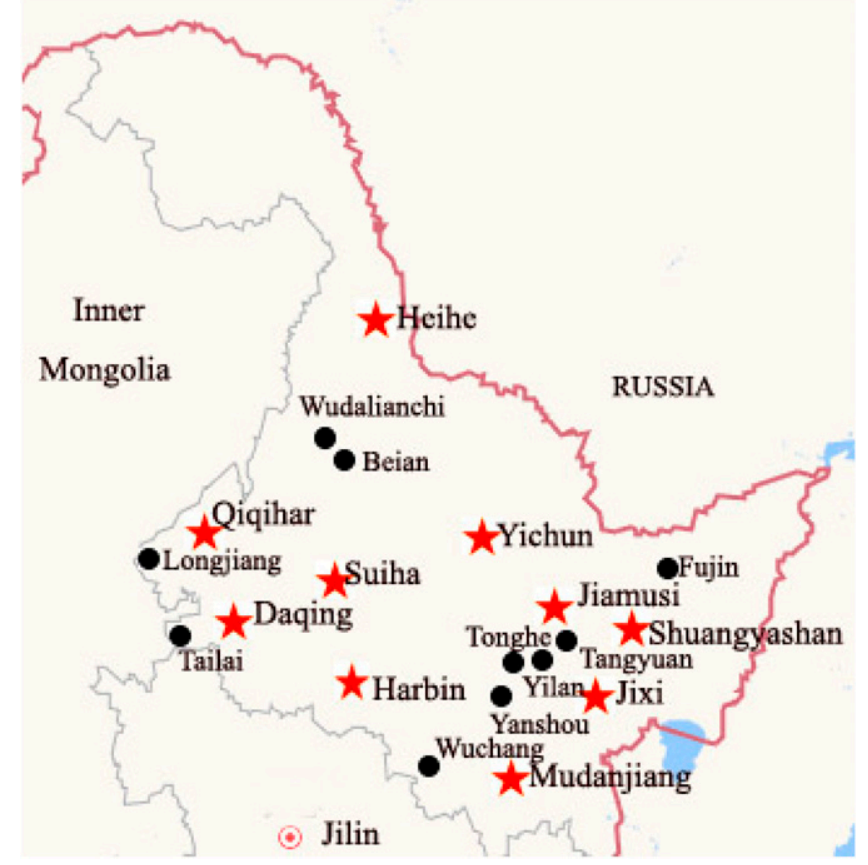

Fig. 1. Sampling locations of rice seedling blight in Heilongjiang Province. Stars indicate disease samples from 10 prefecture-level cities in Heilongjiang Province. Dots indicate specific counties and cities of disease samples.

Table 1. Fungal species and their frequencies identified from rice seedling blight samples from Heilongjiang Province, China

\begin{tabular}{llcc}
\hline No. & \multicolumn{1}{c}{ Pathogen } & Isolates $(\boldsymbol{n})$ & Frequency $(\boldsymbol{\%})$ \\
\hline 1 & Fusarium oxysporum & 108 & 48.0 \\
2 & F. verticillioides & 26 & 11.6 \\
3 & F. tricinctum & 18 & 8.0 \\
4 & F. aromaticum & 15 & 6.7 \\
5 & F. equiseti & 14 & 6.2 \\
6 & F. solani & 14 & 6.2 \\
7 & Rhizoctonia solani & 15 & 6.7 \\
8 & Alternaria alternata & 9 & 4.0 \\
9 & Curvularia trifolii & 6 & 2.7 \\
\hline
\end{tabular}

Disease severity was rated based on a slightly modified 0 to 4 disease index scale (Wang et al. 2009): 0, no symptoms; 1, small lesions at the stem base (covering less than one-quarter of the stem circumference); 2, moderate-sized lesions at the stem base (covering about one-quarter to one-half of the stem circumference); 3 , large lesions at the stem base (covering about one-half to three-quarters of the stem circumference); and 4, dead plants with lesions covering the whole stem circumference. The percent disease index for seedling blight was calculated to determine the pathogenicity of the strains as follows: disease index $<50$, weakly pathogenic; $50 \leq$ disease index $<60$, moderately pathogenic; and disease index $\geq 60$, highly pathogenic.

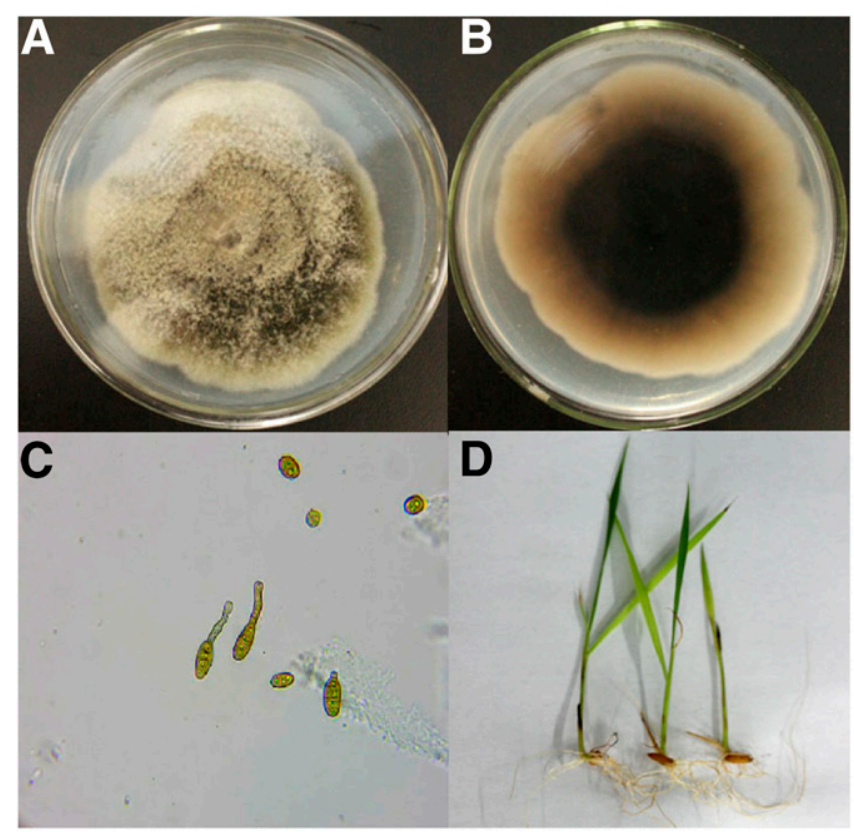

Fig. 2. Alternaria alternata causing rice seedling blight. A, Colony in the front view. B, Colony in the back view. C, Conidia. D, Rice seedling blight caused by A. alternata.

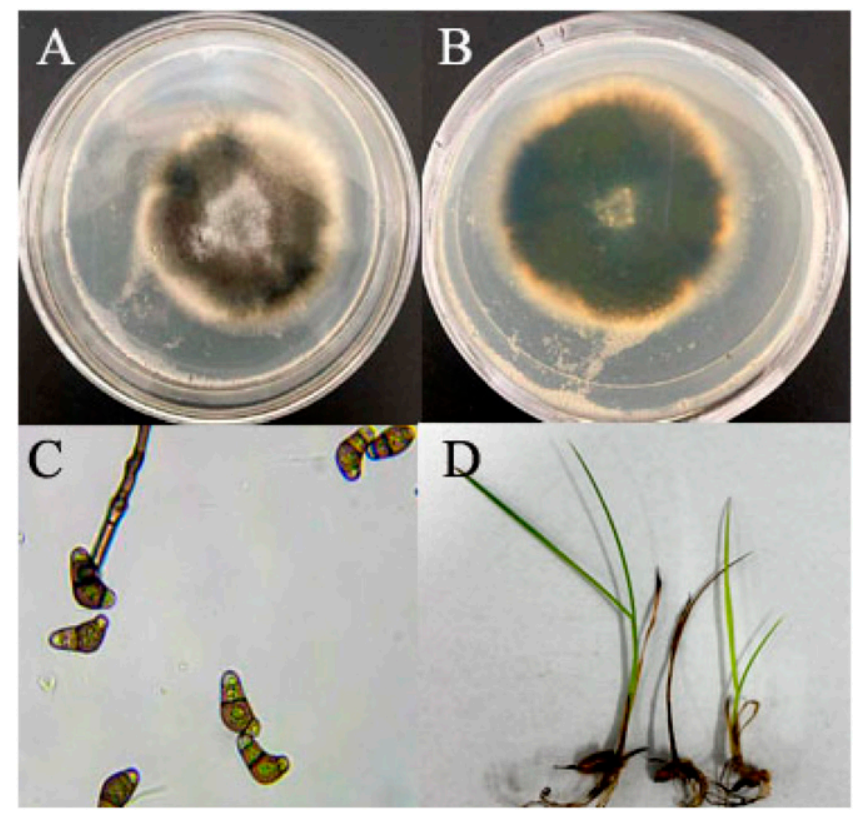

Fig. 3. Curvularia trifolii causing rice seedling blight. A, Colony in the front view. B, Colony in the back view. C, Conidia. D, Rice seedling blight caused by C. trifolii. 
Determining the sensitivity of $F$. oxysporum isolates to carbendazim. Dafusheng (50\% carbendazim WP) provided by Jiangsu Lanfeng Biochemical Co., Ltd. (Xuzhou, China) was mixed with sterile distilled water to prepare a stock solution $(0.004 \mathrm{~g} / \mathrm{ml})$, which was then added to PDA medium for carbendazim concentrations of 0 (control), 1 , and $10 \mathrm{mg} / \mathrm{ml}$ to control the mycelial growth rate ( $\mathrm{Li}$ et al. 2019b). Mycelial plugs of the $74 F$. oxysporum isolates cultured on PDA medium were transferred to carbendazim-amended PDA medium in Petri plates, with three plates per carbendazim concentration. The plates were incubated at $26^{\circ} \mathrm{C}$ for 5 days, after which the colony diameters were measured. Data from two repeated tests were combined to calculate the percentage of resistant (colony diameter $>90 \%$ of that of the control), moderately sensitive (colony diameter 30 to $90 \%$ of that of the control), and sensitive (colony diameter $<30 \%$ of that of the control) isolates.

Determining the genetic diversity of $F$. oxysporum isolates. Genomic DNA was extracted from the $74 F$. oxysporum isolates with the PlantGen DNA Kit (Qiagen, Beijing, China) and quantified with the NanoDrop 2000 spectrophotometer (Thermo Fisher Scientific,
Waltham, MA). Twenty-two primer pairs were designed to analyze the genetic diversity of the isolates.

Each genomic template was amplified by PCR in a $20-\mu 1$ reaction volume containing $0.1 \mathrm{ng}$ of DNA, $2 \mathrm{mM}$ of $\mathrm{MgCl}_{2}, 200 \mu \mathrm{M}$ of each dNTP, $200 \mathrm{nM}$ of each primer, and $0.25 \mathrm{U}$ of Taq DNA polymerase (Invitrogen, Carlsbad, CA). The PCR program was as follows: $96^{\circ} \mathrm{C}$ for $3 \mathrm{~min}$; 35 cycles of $96^{\circ} \mathrm{C}$ for $30 \mathrm{~s}, 50^{\circ} \mathrm{C}$ for $30 \mathrm{~s}$, and $72^{\circ} \mathrm{C} 30 \mathrm{~s}$; and $72^{\circ} \mathrm{C}$ for $10 \mathrm{~min}$. The amplified products were separated in a $6.5 \%$ (vol/vol) acrylamide gel, with DNA Marker 2000 (Qiagen) as the size marker, and visualized by silver staining (Cutts et al. 1984). The gel images were scored as follows: 1, presence of a band; 0 , absence of a band; and 9, missing a band for each variety and marker.

An unweighted pair group method with arithmetic mean (UPGMA) cluster analysis was completed with the NTSYSpc program (version 2.11V) (Kafkas et al. 2008; Rohlf 2004). In addition, an analysis of molecular variance (AMOVA) was conducted with the GenAlEx 6.502 program (Peakall and Smouse 2012). Nei's genetic distance was calculated with PopGen32 software (Nei 1972).
Table 2. Pathogenicity, geographical location, and sensitivity to carbendazim of Fusarium oxysporum isolates from rice in Heilongjiang Province

\begin{tabular}{|c|c|c|c|c|c|c|}
\hline \multirow[b]{2}{*}{ No. } & \multirow[b]{2}{*}{ Group } & \multirow[b]{2}{*}{ Isolate } & \multirow[b]{2}{*}{ Pathogenicity ${ }^{\mathbf{a}}$} & \multirow[b]{2}{*}{ Region } & \multicolumn{2}{|c|}{$\begin{array}{c}\text { Sensitivity to } \\
\text { carbendazim }\end{array}$} \\
\hline & & & & & $\begin{array}{c}1 \\
\mu \mathrm{g} / \mathrm{ml}\end{array}$ & $\begin{array}{c}10 \\
\mu \mathrm{g} / \mathrm{ml}\end{array}$ \\
\hline 1 & I & HYLa & $\mathrm{M}$ & Harbin & $\mathrm{H}$ & $\mathrm{H}$ \\
\hline 2 & & HYLb & $\mathrm{M}$ & Harbin & $\mathrm{H}$ & $\mathrm{H}$ \\
\hline 3 & & HYLc & M & Harbin & $\mathrm{H}$ & $\mathrm{H}$ \\
\hline 4 & & QTLa & M & Qiqihar & $\mathrm{H}$ & $\mathrm{H}$ \\
\hline 5 & & QTLb & $\mathrm{S}$ & Qiqihar & $\mathrm{H}$ & $\mathrm{H}$ \\
\hline 6 & & JXe & $S$ & Jixi & $\mathrm{H}$ & $\mathrm{H}$ \\
\hline 7 & & SYSa & $\mathrm{W}$ & Shuangyashan & $\mathrm{H}$ & $\mathrm{H}$ \\
\hline 8 & & SYSh & W & Shuangyashan & $\mathrm{H}$ & $\mathrm{H}$ \\
\hline 9 & & MDJa & $S$ & Mudanjiang & $\mathrm{H}$ & $\mathrm{H}$ \\
\hline 10 & & MDJb & $\mathrm{W}$ & Mudanjiang & $\mathrm{H}$ & $\mathrm{H}$ \\
\hline 11 & & MDJc & M & Mudanjiang & $\mathrm{H}$ & I \\
\hline 12 & & MDJd & M & Mudanjiang & $\mathrm{H}$ & I \\
\hline 13 & & HTHc & M & Harbin & $\mathrm{H}$ & I \\
\hline 14 & & HYSa & W & Harbin & $\mathrm{H}$ & I \\
\hline 15 & & $\mathrm{HWCb}$ & $\mathrm{W}$ & Harbin & $\mathrm{H}$ & I \\
\hline 16 & & $\mathrm{JXd}$ & $\mathrm{W}$ & Jixi & $\mathrm{H}$ & I \\
\hline 17 & & $\mathrm{JXg}$ & W & Jixi & $\mathrm{H}$ & $\mathrm{H}$ \\
\hline 18 & & $\mathrm{SYSb}$ & $\mathrm{S}$ & Shuangyashan & $\mathrm{H}$ & I \\
\hline 19 & & SYSe & M & Shuangyashan & $\mathrm{H}$ & $\mathrm{H}$ \\
\hline 20 & & SYSf & M & Shuangyashan & $\mathrm{H}$ & I \\
\hline 21 & & $\mathrm{SYSc}$ & $\mathrm{W}$ & Shuangyashan & $\mathrm{H}$ & $\mathrm{H}$ \\
\hline 22 & & $\mathrm{JXa}$ & $\mathrm{W}$ & Jixi & $\mathrm{H}$ & I \\
\hline 23 & & SYSi & $\mathrm{S}$ & Shuangyashan & $\mathrm{H}$ & I \\
\hline 24 & & $\mathrm{JXb}$ & M & Jixi & $\mathrm{H}$ & I \\
\hline 25 & & SYSg & M & Shuangyashan & $\mathrm{H}$ & I \\
\hline 26 & & $\mathrm{YCa}$ & $\mathrm{S}$ & Yichun & $\mathrm{H}$ & $\mathrm{H}$ \\
\hline 27 & & SYSj & M & Shuangyashan & $\mathrm{H}$ & I \\
\hline 28 & & HWDLCa & M & Heihe & $\mathrm{H}$ & I \\
\hline 29 & & HWDLCd & M & Heihe & $\mathrm{H}$ & $\mathrm{H}$ \\
\hline 30 & & HWDLCc & $\mathrm{S}$ & Heihe & $\mathrm{H}$ & I \\
\hline 31 & & HWDLCe & M & Heihe & $\mathrm{H}$ & I \\
\hline 32 & & HWDLCb & $S$ & Heihe & $\mathrm{H}$ & $\mathrm{H}$ \\
\hline 33 & & $\mathrm{HYSb}$ & M & Harbin & $\mathrm{H}$ & I \\
\hline
\end{tabular}

a Pathogenicity of the strains: $\mathrm{W}=$ disease index $<50$ indicates weak pathogenicity, $M=50 \leq$ disease index $<60$ indicates moderate pathogenicity, and $\mathrm{S}=$ disease index $\leq 60$ indicates strong pathogenicity.

b Sensitivity to carbendazim was determined based on in vitro mycelial growth. $\mathrm{H}=$ percentage of resistant isolates (colony diameter $>90 \%$ of the control) and $\mathrm{I}=$ percentage of intermediately sensitive isolates (30 to $90 \%$ of the control). Data from two repeated tests were pooled for percentage of resistant or sensitive isolates.
Table 2. (Continued)

\begin{tabular}{|c|c|c|c|c|c|c|}
\hline \multirow[b]{2}{*}{ No. } & \multirow[b]{2}{*}{ Group } & \multirow[b]{2}{*}{ Isolate } & \multirow[b]{2}{*}{ Pathogenicity ${ }^{\mathrm{a}}$} & \multirow[b]{2}{*}{ Region } & \multicolumn{2}{|c|}{$\begin{array}{l}\text { Sensitivity to } \\
\text { carbendazim }\end{array}$} \\
\hline & & & & & $\begin{array}{c}1 \\
\mu \mathrm{g} / \mathrm{ml}\end{array}$ & $\begin{array}{c}10 \\
\mu \mathrm{g} / \mathrm{ml}\end{array}$ \\
\hline 34 & & HYSf & M & Harbin & $\mathrm{H}$ & I \\
\hline 35 & & HYSd & $\mathrm{S}$ & Harbin & $\mathrm{H}$ & I \\
\hline 36 & & HYSe & M & Harbin & $\mathrm{H}$ & $\mathrm{H}$ \\
\hline 37 & & HTHd & M & Harbin & $\mathrm{H}$ & I \\
\hline 38 & & HBAd & M & Heihe & $\mathrm{H}$ & I \\
\hline 39 & & $\mathrm{JTYb}$ & M & Jiamusi & $\mathrm{H}$ & I \\
\hline 40 & & JTYc & M & Jiamusi & $\mathrm{H}$ & I \\
\hline 41 & & JTYd & M & Jiamusi & $\mathrm{H}$ & I \\
\hline 42 & II & НТНа & M & Harbin & $\mathrm{H}$ & I \\
\hline 43 & & HTHb & $\mathrm{M}$ & Harbin & $\mathrm{H}$ & $\mathrm{H}$ \\
\hline 44 & & HBAc & M & Heihe & $\mathrm{H}$ & $\mathrm{H}$ \\
\hline 45 & III & YCc & M & Yichun & $\mathrm{H}$ & $\mathrm{H}$ \\
\hline 46 & & YCd & M & Yichun & $\mathrm{H}$ & $\mathrm{H}$ \\
\hline 47 & & $\mathrm{YCe}$ & S & Yichun & $\mathrm{H}$ & $\mathrm{H}$ \\
\hline 48 & & $\mathrm{YCg}$ & M & Yichun & $\mathrm{H}$ & $\mathrm{H}$ \\
\hline 49 & & $\mathrm{YCh}$ & S & Yichun & $\mathrm{H}$ & $\mathrm{H}$ \\
\hline 50 & & $\mathrm{YCi}$ & M & Yichun & $\mathrm{H}$ & $\mathrm{H}$ \\
\hline 51 & IV & $\mathrm{JXc}$ & S & Jixi & $\mathrm{H}$ & $\mathrm{H}$ \\
\hline 52 & & SYSd & M & Shuangyashan & $\mathrm{H}$ & $\mathrm{H}$ \\
\hline 53 & & JXh & $\mathrm{M}$ & Jixi & $\mathrm{H}$ & $\mathrm{H}$ \\
\hline 54 & V & SHa & M & Suihua & $\mathrm{H}$ & $\mathrm{H}$ \\
\hline 55 & & $\mathrm{SHc}$ & S & Suihua & $\mathrm{H}$ & $\mathrm{H}$ \\
\hline 56 & & SHd & M & Suihua & $\mathrm{H}$ & $\mathrm{H}$ \\
\hline 57 & & $\mathrm{SHb}$ & M & Suihua & $\mathrm{H}$ & $\mathrm{H}$ \\
\hline 58 & VI & QLJb & $\mathrm{S}$ & Qiqihar & $\mathrm{H}$ & I \\
\hline 59 & & QLJd & M & Qiqihar & $\mathrm{H}$ & I \\
\hline 60 & & QLJe & S & Qiqihar & $\mathrm{H}$ & I \\
\hline 61 & & QLJc & S & Qiqihar & $\mathrm{H}$ & $\mathrm{H}$ \\
\hline 62 & & DQc & M & Daqing & $\mathrm{H}$ & I \\
\hline 63 & & DQf & M & Daqing & $\mathrm{H}$ & $\mathrm{H}$ \\
\hline 64 & & DQg & S & Daqing & $\mathrm{H}$ & I \\
\hline 65 & & DQi & $S$ & Daqing & $\mathrm{H}$ & $\mathrm{H}$ \\
\hline 66 & & DQj & $S$ & Daqing & $\mathrm{H}$ & I \\
\hline 67 & VII & JFJa & $\mathrm{M}$ & Jiamusi & $\mathrm{H}$ & $\mathrm{H}$ \\
\hline 68 & & $\mathrm{JFJb}$ & $S$ & Jiamusi & $\mathrm{H}$ & I \\
\hline 69 & & JFJd & M & Jiamusi & $\mathrm{H}$ & I \\
\hline 70 & & JFJe & $\mathrm{S}$ & Jiamusi & $\mathrm{H}$ & $\mathrm{H}$ \\
\hline 71 & VIII & DQe & $\mathrm{S}$ & Daqing & $\mathrm{H}$ & I \\
\hline 72 & & DQh & S & Daqing & $\mathrm{H}$ & $\mathrm{H}$ \\
\hline 73 & IX & QLJf & S & Qiqihar & $\mathrm{H}$ & I \\
\hline 74 & & QLJh & M & Qiqihar & $\mathrm{H}$ & I \\
\hline
\end{tabular}




\section{Results}

Isolation and identification of pathogenic fungi. A total of 225 fungal strains were isolated from diseased rice seedlings collected from 16 locations in 10 prefecture-level cities in Heilongjiang Province (Fig. 1). These isolates were identified as the following species (Table 1): $108 \mathrm{~F}$. oxysporum isolates $(48.0 \%), 26 \mathrm{~F}$. verticillioides (Sacc.) Nirenberg isolates (11.6\%), 18 F. tricinctum (Corda) Sacc. isolates $(8.0 \%), 15 \mathrm{~F}$. redolens Wollenw. isolates $(6.7 \%), 14 \mathrm{~F}$. equiseti (Corda) Sacc. isolates (6.2\%), 14 F. solani (Mart.) Sacc. isolates (6.2\%), 15 Rhizoctonia solani J. G. Kühn isolates (6.7\%), 9 Alternaria alternata (Fr.) Keissl. isolates (4.0\%), and 6 C. coatesiae Y. P. Tan \& R. G. Shivas isolates (2.7\%). Thus, F. oxysporum was identified as the dominant fungus causing rice seedling blight, with most isolates moderately pathogenic.

Morphological characteristics were used to identify the nine $A$. alternata isolates (Bihon et al. 2015) (Fig. 2) and six C. coatesiae isolates (Tan et al. 2018) (Fig. 3). Genomic DNA was extracted from single-conidium cultures of representative isolates SL7 and SL22, after which the ITS regions were amplified by PCR with universal fungal primers ITS1 and ITS4 (Yin et al. 2012). The PCR products were sequenced and deposited in the GenBank database (accession numbers MN134489 and MN134490 for SL7 and SL22 sequences, respectively). A MegaBLAST analysis revealed that the SL7 sequence was $99 \%$ similar to a sequence in A. alternata isolate Alt22 (accession number MH844085.1), whereas the SL22 sequence was identical to a sequence in C. coatesiae strain BRIP24261 (accession number MH414897.1). To our knowledge, this is the first report describing A. alternata and $C$. coatesiae as the causal agent of rice seedling blight in Northeast China.

Pathogenicity determination. Differences in pathogenicity were detected among the 74 analyzed single-spore isolates of $F$. oxysporum (Table 2). For example, 25 isolates were highly pathogenic (e.g., JXe, HWDLCb, and HWDLCc), with most (71.4\%) from samples collected at Daqing. In addition, 10 isolates were weakly pathogenic (e.g., SYSh, SYSc, and JXg). The remaining isolates were moderately pathogenic, with most $(76.9 \%)$ derived from samples collected at Harbin. Thus, most of the $F$. oxysporum isolates causing rice seedling blight were moderately pathogenic.

Determining the sensitivity of $F$. oxysporum isolates to carbendazim. All isolates were highly resistant to $1 \mathrm{mg} / \mathrm{ml}$ of carbendazim (Table 2). Regarding the effects of $10 \mathrm{mg} / \mathrm{ml}$ of carbendazim, 51.4 and $48.6 \%$ of the isolates were highly and moderately resistant, respectively, and none of the isolates were sensitive.

Determining the genetic diversity of single-spore isolates of F. oxysporum. Of the 22 pairs of SSR primers tested, 14 pairs generated reproducible polymorphic bands (Table 3 ). The genetic similarity coefficients among the 74 single-spore isolates of $F$. oxysporum ranged from 0.58 to 0.98 , with a mean of 0.78 . When the genetic similarity coefficient was set to 0.79 , the UPGMA analysis clustered the singlespore isolates into the following nine SSR groups (Fig. 4; Table 2). Group I contained 41 isolates (11 from Harbin, two from Qiqihar, five from Jixi, nine from Shuangyashan, four from Mudanjiang, one from Yichun, six from Heihe, and three from Jiamusi). Group II comprised three isolates (two from Harbin and one from Heihe). Group III included six isolates from Yichun. Group IV contained two isolates from Jixi and one isolate from Shuangyashan. Group V consisted of four isolates from Suihua. Group VI contained four isolates from Qiqihar and five isolates from Daqing. Group VII comprised four isolates from Jiamusi. Group VIII included two isolates from Daqing. Finally, group IX contained two isolates from Qiqihar (Fig. 2).

The AMOVA results revealed a significant correlation between the population and geographical origin $(P=0.001)$, between the population and pathogenicity $(P=0.030)$, and between the population and susceptibility to $10 \mu \mathrm{g} / \mathrm{ml}$ of carbendazim $(P=0.031)$ (Table 4$)$. The fixed index $\left(F_{S T}\right)$ was used to assess the extent of the genetic differentiation among populations. $F_{S T}$ values ranging from 0 to 0.05 indicated minimal genetic differentiation, whereas values between 0.05 and 0.15 corresponded to a moderate genetic differentiation and values between 0.15 and 0.25 were indicative of a large genetic differentiation. Moreover, $F_{S T}$ values exceeding 0.25 corresponded to a very substantial genetic differentiation (Hartl and Clark 1997). The very substantial genetic differentiation among populations with

Table 3. Primers used in SSR analysis of Fusarium oxysporum isolates

\begin{tabular}{|c|c|c|c|c|}
\hline Primer & Sequence $5^{\prime}$ to $3^{\prime a}$ & Repeat motif & Scored alleles $(n)$ & Allele size (bp) \\
\hline \multirow[t]{2}{*}{ Foc7 } & F: CAAGTCAGCAACCAACACAACT & $(\mathrm{CGG})_{4}$ & 8 & $180,286,395,430,500,675,700,175$ \\
\hline & R: GTCСТCССАТТСТTCTАССАСС & & & \\
\hline \multirow[t]{2}{*}{ Fol2 } & F: CTCGCATACTACTACCGCACAG & $(\mathrm{CAG})_{10}$ & 7 & $100,145,205,250,418,480,1,500$ \\
\hline & R: GCAGATAAGGGAGATGCAAAAC & & & \\
\hline \multirow[t]{2}{*}{ Fol4 } & F: CCAGTCAATCCAACCCTTACTT & $(\mathrm{ACCA})_{3}$ & 8 & $150,200,300,450,500,700,950,1,600$ \\
\hline & R: AGGCTTATCTGCGTCAGTTTCT & & & \\
\hline \multirow[t]{2}{*}{ JB12 } & F: CGGATGGTGTTTCTGTGC & $(\mathrm{AT})_{9}$ & 6 & $124,188,226,250,425,520$ \\
\hline & R: CCAACCCGAACCCTACTT & & & \\
\hline \multirow[t]{2}{*}{ JB18 } & F: TTCCTTTCCСТCCTGTTT & $(\mathrm{ATAC})_{5}$ & 6 & $275,410,450,550,650,725$ \\
\hline & R: ACTCCTTCCTGGCTCAAT & & & \\
\hline \multirow[t]{2}{*}{ JB20 } & F: CGTATTGCCAGGTAGGTT & $(\mathrm{TTC})_{9}$ & 5 & $270,310,350,525,625$ \\
\hline & R: CGTATTGCCAGGTAGGTT & & & \\
\hline \multirow[t]{2}{*}{ JB24 } & F: CCTGTCGCAATGGGTATC & $(\mathrm{GAG})_{6}$ & 5 & $200,550,600,900,950$ \\
\hline & R: AGTGTCTCCTTGGGGTCG & & & \\
\hline \multirow[t]{2}{*}{ JB25 } & F: GCACCTCCACCACCAATG & $(\mathrm{AC})_{15}$ & 1 & 255 \\
\hline & R: AAACTCGCTCTTCGCTCC & & & \\
\hline \multirow[t]{2}{*}{ JB27 } & F: CGCACCTCCACCACCAAT & $(\mathrm{AC})_{15}$ & 3 & $120,140,156$ \\
\hline & R: TTCCGAGCAGACGCCAAT & & & \\
\hline \multirow[t]{2}{*}{ JB007 } & F: CGGATGGTGTTTCTGTGC & $(\mathrm{AT})_{9}$ & 1 & 160 \\
\hline & R: CCAACCCGAACCCTACTT & & & \\
\hline \multirow[t]{2}{*}{ JB016 } & F: TCCACCACCAATGACAAAC & $(\mathrm{AC})_{15}$ & 6 & $140,200,275,375,580,800$ \\
\hline & R: AACTCCGTGAGACGAAACT & & & \\
\hline \multirow[t]{2}{*}{ JB39 } & F: TTCCTTTCCCTCCTGTTT & $(\mathrm{ATAC})_{5}$ & 5 & $300,400,450,700,1,000$ \\
\hline & R: ACTCCTTCCTGGCTCAAT & & & \\
\hline \multirow[t]{2}{*}{ JB41 } & F: TATGCTGGATGGTGAAGG & $(\mathrm{ACAA})_{5}$ & 6 & $135,185,240,245,255,875$ \\
\hline & R: GCTATGCGAGGATTTTGT & & & \\
\hline \multirow[t]{2}{*}{ JB46 } & F: CAAACAACCCTCTATGCC & $(\mathrm{AC})_{15}$ & 4 & $200,300,425,450$ \\
\hline & R: ACTCCGTGAGACGAAACT & & & \\
\hline
\end{tabular}

\footnotetext{
${ }^{\mathrm{a}} \mathrm{F}=$ forward and $\mathrm{R}=$ reverse.
} 
diverse geographical origins $\left(F_{S T}=0.374\right)$ implied that the various sample collection locations in Heilongjiang Province significantly influenced the population differentiation of the dominant fungal strains causing rice seedling blight (Table 4).

Pairwise comparisons of the population differentiation $\left(F_{S T}\right)$ for the $F$. oxysporum sample collection locations supported the UPGMA results (Table 5). Specifically, there were significant differences among the sampling locations, pathogenicity, and sensitivity to carbendazim. For the 10 sample collection locations, the shortest genetic distance (0.031) was between the Harbin and Jixi populations, whereas the greatest genetic distance (4.135) was between the Suihua and Mudanjiang populations. These results suggested that the genetic relationship between populations with diverse geographical origins is related to the geographical distance.

\section{Discussion}

Rice seedling blight has been responsible for severe decreases in rice yield and quality in many countries (Baek et al. 2019; Imolehin

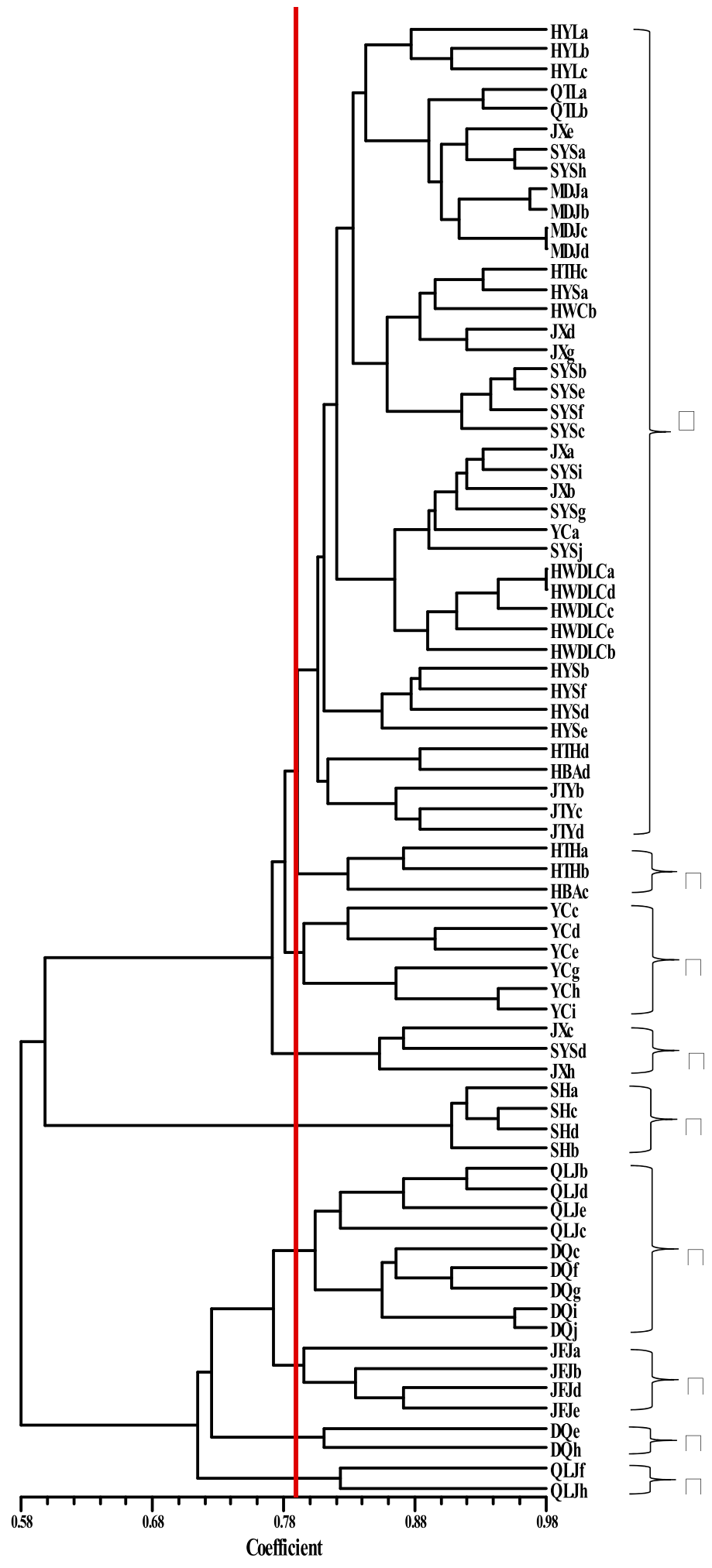

Fig. 4. Unweighted pair group method with arithmetic mean dendrogram of 74 isolates of Fusarium oxysporum based on simple sequence repeat markers amplified using 14 primer pairs. 
1983). The dominant species causing rice seedling blight varies depending on the geographical location, with previous studies identifying the following as the dominant species: Helminthosporium oryzae and Pyricularia oryzae in India (Kannaiyan and Radhaokrishnan 2013), F. moniliforme in Anhui, China (Gao et al. 2001), Xanthomonas oryzae pv. oryzae in Pakistan (Naveed et al. 2010), B. glumae and B. gladioli in Colombia (Fory et al. 2014; Pedraza et al. 2018), and $F$. graminearum in Korea (Kim et al. 2018). In the current study, $F$. oxysporum was identified as the dominant fungal species causing rice seedling blight in Northeast China. The data presented herein may be useful for developing effective disease management strategies and for breeding new disease-resistant rice varieties. Therefore, monitoring the population structure and pathogenicity of the pathogens causing rice seedling blight in various rice-producing regions is important. Furthermore, to our knowledge, this is the first report describing A. alternata and C. coatesiae as causal agents of rice seedling blight in Northeast China. The incidence of this disease needs to be carefully monitored to ensure that effective disease management strategies are implemented to maintain rice production.

The pathogens causing rice seedling blight are complex and differ depending on the location, which makes controlling this disease challenging. Nevertheless, chemical treatments remain the most effective way to control this disease. Carbendazim has been one of the main chemicals used to manage rice diseases caused by Fusarium spp. for many years (Ahuja et al. 2019; Bai et al. 2001; Wang et al. 2011). Because of the sensitivity of Fusarium spp. to benzimidazole fungicides, controlling these fungal species with chemicals can be difficult (Ma et al. 2003). In the current study, all tested $F$. oxysporum isolates were highly resistant to $1 \mathrm{mg} / \mathrm{ml}$ of carbendazim. In addition, $51.4 \%$ of the isolates were also highly resistant to $10 \mathrm{mg} / \mathrm{ml}$ of carbendazim, and none of the isolates were sensitive to this concentration. Therefore, carbendazim is not suitable for controlling rice seedling blight in Northeast China.
Of the available molecular marker systems, those involving SSR markers are among the most popular because of their highly desirable properties (e.g., marker abundance, hypervariability, and suitability for high-throughput analyses) (Kumar et al. 2012). For example, Pouralibaba et al. (2019) used eight SSR markers to analyze the diversity of $F$. oxysporum f. sp. lentis. Their results revealed the high molecular variability of this fungal species within regions and indicated that Iran may be a center of origin for $F$. oxysporum f. sp. lentis. Moreover, Cruz et al. (2018) used seven SSR markers to analyze the diversity of $F$. oxysporum f. sp. phaseoli, which causes Fusarium wilt of common bean. Their data indicated that the genetic diversity of this fungal species is positively correlated with its virulence to common bean. These findings are basically consistent with our results. In the current study, $74 F$. oxysporum isolates were divided into nine groups based on an SSR analysis with 14 primer pairs. Furthermore, the AMOVA data revealed a significant correlation between the F. oxysporum population and geographical location, pathogenicity, and sensitivity to carbendazim. The geographical location of isolates significantly influenced the differentiation of the dominant isolate population in Northeast China. In other words, our SSR markers were able to determine the extent of the genetic diversity among the fungi responsible for rice seedling blight. Our findings also confirm the importance of monitoring the population structure of strains from various geographical locations.

In conclusion, the population structure of pathogenic fungi causing rice seedling blight is complex and the incidence of this disease needs to be carefully monitored to ensure that effective disease management strategies are applied. The data generated in this study based on SSR markers may be relevant for future genomic analyses of $F$. oxysporum regarding evolution, diversity, population genetics, geographical origins, pathogenicity, and susceptibility to chemical fungicides.

Table 4. Hierarchical partitioning of variance among and within population groups of Fusarium oxysporum isolates based on analysis of molecular variance

\begin{tabular}{|c|c|c|c|c|c|c|}
\hline Source of variation & $d f^{\mathrm{a}}$ & Sum of squares & Variance component & Variation (\%) & $F_{S T}^{\mathbf{b}}$ & $P$ \\
\hline \multicolumn{7}{|l|}{ Geographical location ${ }^{\mathrm{c}}$} \\
\hline Among groups & 9 & 383.8 & 4.75 & 37.42 & 0.374 & 0.001 \\
\hline Within groups & 64 & 508.3 & 7.94 & 62.58 & & \\
\hline \multicolumn{7}{|l|}{ Pathogenicity ${ }^{\mathrm{d}}$} \\
\hline Among groups & 2 & 42.56 & 0.42 & 3.39 & & \\
\hline Within groups & 71 & 849.54 & 11.97 & 96.61 & 0.034 & 0.030 \\
\hline \multicolumn{7}{|l|}{ Susceptibility ${ }^{\mathrm{e}}$} \\
\hline Among groups & 1 & 23.82 & 0.32 & 2.57 & & \\
\hline Within groups & 72 & 868.27 & 12.06 & 97.43 & 0.026 & 0.031 \\
\hline
\end{tabular}

a $d f=$ degrees of freedom.

${ }^{\mathrm{b}} F_{S T}=$ Fixed index.

${ }^{\mathrm{c}}$ Geographical locations included Harbin, Suihua, Qiqihar, Heihe, Shuangyashan, Yichun, and Jiamusi.

d Physiological race included $0,1,2,3,3 \mathrm{~N}, 12,13,23$, and $\mathrm{N}$.

e Mating type included a, Aa, and A.

Table 5. Pairwise fixation index values for geographical location of Fusarium oxysporum isolates

\begin{tabular}{|c|c|c|c|c|c|c|c|c|c|c|}
\hline Region $(n)^{\mathbf{a}}$ & $\mathbf{H}^{\mathbf{b}}$ & $\mathbf{Q}^{\mathbf{b}}$ & $\mathbf{J}^{\mathbf{b}}$ & $\mathbf{S Y} \mathbf{Y}^{\mathbf{b}}$ & $\mathbf{D}^{\mathbf{b}}$ & $\mathbf{Y}^{\mathbf{b}}$ & $\mathbf{J T}^{\mathbf{b}}$ & $\mathbf{M}^{\mathbf{b}}$ & $\mathbf{S H}^{\mathbf{b}}$ & $\mathbf{H B}^{\mathbf{b}}$ \\
\hline H (13) & 0.000 & & & & & & & & & \\
\hline Q (8) & $0.552^{* *}$ & 0.000 & & & & & & & & \\
\hline $\mathrm{J}(7)$ & 0.031 & $0.500 * *$ & 0.000 & & & & & & & \\
\hline SY (10) & $0.104 * *$ & $0.727 * *$ & 0.055 & 0.000 & & & & & & \\
\hline D (7) & $1.254 * *$ & $0.276^{* *}$ & $1.175^{* *}$ & $1.588 * *$ & 0.000 & & & & & \\
\hline Y (7) & $0.169^{* *}$ & $0.481 * *$ & $0.232 * *$ & $0.330 * *$ & $1.165^{* *}$ & 0.000 & & & & \\
\hline JT (7) & $0.362 * *$ & $0.089^{*}$ & $0.291 *$ & $0.494 * *$ & $0.245^{* *}$ & $0.302 *$ & 0.000 & & & \\
\hline M (4) & $0.298 * *$ & $0.712 * *$ & $0.336 * *$ & $0.585 * *$ & $2.034 * *$ & $0.243^{* *}$ & $0.495 * *$ & 0.000 & & \\
\hline SH (4) & $1.495^{* *}$ & $1.088 * *$ & $1.706 * *$ & $2.417 * *$ & $2.274 * *$ & $1.505^{* *}$ & $0.905 * *$ & $4.135^{*}$ & 0.000 & \\
\hline HB (7) & $0.213 * *$ & $0.632 * *$ & $0.150 *$ & $0.310 * *$ & $1.458 * *$ & $0.188 * *$ & $0.356^{* *}$ & $0.419 * *$ & $2.176^{* *}$ & 0.000 \\
\hline
\end{tabular}

a Ten geographical locations, including Harbin (H), Qiqihar (Q), Jixi (J), Shuangyashan (SY), Daqing (D), Yichun (Y), Jiamusi (JT), Mudanjiang (M), Suihua $(\mathrm{SH})$, and Heihe $(\mathrm{HB})$. The number of isolates is indicated in parentheses.

b Nei's genetic distance (below diagonal). Values are significantly different at $* P<0.05$ and $* * P<0.01$. 


\section{Literature Cited}

Ahuja, R., Sidhu, A., and Bala, A. 2019. Synthesis and evaluation of iron(ii) sulfide aqua nanoparticles (FeS-NPs) against Fusarium verticillioides causing sheath rot and seed discoloration of rice. Eur. J. Plant Pathol. 155:163.

Aye, S. S., Fukuda, S., and Matsumoto, M. 2008. Chemotaxonomic characterization of rice seedling blight complex using fatty acid methyl ester (FAME) profiles. Mycoscience 49:373.

Baek, I., Kim, M. S., Cho, B. K., Mo, C., Barnaby, J. Y., McClung, A. M., and Oh, M. 2019. Selection of optimal hyperspectral wavebands for detection of discolored, diseased rice seeds. Appl. Sci. (Basel) 9:1027.

Bai, Q. R., Gao, J., Yu, R. H., and Wang, Y. Q. 2001. Control of rice seedling blight by kekuling. J. Jilin Agric. Univ. 23:31-34.

Bihon, W., Cloete, M., Gerrano, A., Adebola, P., and Oelofse, D. 2015. First report of Alternaria alternata causing leaf blight of onion in South Africa. Plant Dis. 99:1652.

Booth, C. 1971. The Genus Fusarium. 12:1-6. Commonwealth Mycological Institute, Kew, Surrey.

Cruz, A. F., Silva, L. F., Sousa, T. V., Nicoli, A., and de Paula, T. J., Jr. 2018. Molecular diversity in Fusarium oxysporum isolates from common bean fields in Brazil. Eur. J. Plant Pathol. 152:343-354.

Cutts, J. L., Sweet, G. H., and Tegtmeier, G. E. 1984. The use of silver stain in sodium dodecyl sulfate polyacrylamide gel electrophoresis of immunoprecipitates obtained by crossed immunoelectrophoresis and liquid precipitation. Electrophoresis 5: 349-353.

Dossou, B., and Silue, D. 2018. Rice pathogens intercepted on seeds originating from 11 African countries and from the USA. Seed Sci. Technol. 46:31-40.

Fory, P. A., Triplett, L., Ballen, C., Abello, J. F., Duitama, J., Aricapa, M. G., Prado, G. A., Correa, F., Hamilton, J., Leach, J. E., Tohme, J., and Mosquera, G. M. 2014. Comparative analysis of two emerging rice seed bacterial pathogens. Phytopathology 104:436-444.

Gao, T. C., Ye, Z. Y., Wang, M., and Ma, Y. M. 2001. Identification and pathogenicity test of pathogenic Fusarium of rice blight. Chin. J. Rice Sci. 15:320-322.

Hartl, D. L., and Clark, A. G. 1997. Principles of Population Genetics, 3rd ed. Sinauer Associates Inc., Sunderland, MA.

Hiremani, N. S., and Dubey, S. C. 2019. Genetic diversity of Fusarium oxysporum f. sp. lentis populations causing wilt of lentil in India. Indian Phytopathol. https://doi.org/10.1007/s42360-019-00126-9.

Huzar-Novakowiski, J., and Dorrance, A. E. 2018. Genetic diversity and population structure of Pythium irregulare from soybean and corn production fields in Ohio. Plant Dis. 102:1989-2000.

Imolehin, E. D. 1983. Rice seed borne fungi and their effect on seed germination. Plant Dis. 67:1334-1336.

Ivors, K., Garbelotto, M., Vries, I. D., Ruyter-Spira, C., Te Hekkert, B., Rosenzweig, N., and Bonants, P. 2006. Microsatellite markers identify three lineages of Phytophthora ramorum in US nurseries, yet single lineages in US forest and European nursery populations. Mol. Ecol. 15:1493-1505.

Kafkas, S., Özgen, M., Dog, Y., Ozcan, B., Ercisli, S., and Serce, S. 2008. Molecular characterization of mulberry accessions in Turkey by AFLP marker. J. Am. Soc. Hortic. 133:593-597.

Kannaiyan, S., and Radhaokrishnan, T. 2013. Effect of seed treatment with chemicals on the control of brown leaf spot and blast disease of rice in seedling stage. Madras Agric. J. 69:769-770.

Kim, Y., Kang, I. J., Shin, D. B., Roh, J. H., Heu, S., and Shim, H. K. 2018. Timing of Fusarium head blight infection in rice by heading stage. Mycobiology 46:283-286.

Kumar, S., Maurya, D., Rai, S., Kashyap, P. L., and Srivastava, A. K. 2012. Computational mining and genome wide distribution of microsatellite in Fusarium oxysporum f. sp. lycopersici. Not. Sci. Biol. 4:127-131.

Lees, A. K., Wattier, R., Shaw, D. S., Sullivan, L., Williams, N. A., and Cooke, D. E. L. 2006. Novel microsatellite markers for the analysis of Phytophthora infestans populations. Plant Pathol. 55:311-319.

Li, W. X., Li, H. Y., Cai, D. L., Sang, H. Y., and Chen, T. Y. 2016. The inducedresistance of Harpin on rice seedling blight. J. Anhui Agric. Sci. 44:186-187.

Li, Y. G., Wang, R. T., Liu, J. X., Xu, L. K., Ji, P. S., Sun, L., Pan, H. Y., Jiang, B. W., and Li, L. R. 2019b. Identification of a biocontrol agent Bacillus vallismortis BV23 and assessment of effects of its metabolites on Fusarium graminearum causing corn stalk rot. Biocontrol Sci. Technol. 29:263-275.

Li, Y. G., Zhang, X., Zhang, R., Liu, J. X., Ali, E., Ji, P. S., and Pan, H. Y. 2019a. Occurrence of seedling blight caused by Fusarium tricinctum on rice in China. Plant Dis. 103:1789.
Ma, Z., Yoshimura, M. A., and Michailides, T. J. 2003. Identification and characterization of benzimidazole resistance in Monilinia fructicola from stone fruit orchards in California. Appl. Environ. Microbiol. 69:7145-7152.

Majumder, S., and Banik, P. 2019. Geographical variation of arsenic distribution in paddy soil, rice and rice-based products: A meta-analytic approach and implications to human health. J. Environ. Manage. 233:184-199.

Mishra, R. K., Pandey, B. K., Singh, V., Mathew, A. J., Pathak, N., and Zeeshan, M. 2013. Molecular detection and genotyping of Fusarium oxysporum f. sp. psidii isolates from different agro-ecological regions of India. J. Microbiol. 51:405-412.

Naveed, S. A., Babar, M., Arif, A., Zafar, Y., Sabar, M., Ali, I., Chragh, M., and Arif, M. 2010. Detection of bacterial blight resistant gene $x a 5$ using linked marker approaches. Afr. J. Biotechnol. 9:3549-3554.

Nei, M. 1972. Genetic distance between populations. Am. Nat. 106:283-292.

Nelson, P. E., Toussoun, T. A., and Marasas, W. F. O. 1983. Fusarium Species, An Illustrated Manual for Identification. Pennsylvania State University, University Park.

Peakall, R., and Smouse, P. E. 2012. GenAlEx 6.5: Genetic Analysis in Excel. Population genetic software for teaching and research-An update Bioinformatics 28:2537-2539.

Pedraza, L. A., Bautista, J., and Uribe-Velez, D. 2018. Seed-born Burkholderia glumae infects rice seedling and maintains bacterial population during vegetative and reproductive growth stage. Plant Pathol. J. 34:393-405.

Pouralibaba, H. R., Šatović, Z., Cobos, M. J., Rubiales, D., and Fondevilla, S. 2019. Genetic diversity and structure of Fusarium oxysporum f.sp. lentis isolates from Iran, Syria and Algeria. Eur. J. Plant Pathol. 153:1019-1029.

Riera-Ruiz, C., Castro-Lara, J., Jimenez-Feijoo, M. I., and Cevallos-Cevallos, J. M. 2018. Interactions of Burkholderia glumae and B. gladioli in symptom development in rice seeds and seedlings. Can. J. Plant Pathol. 40:347-357.

Rohlf, F. J. 2004. NTSYS-pc: Numerical Taxonomy and Multivariate Analysis System, Version 2.11V. Exeter Software, Setauket, NY.

Rush, M. C. 1977. Chemical control of rice seedling disease. Annua Prog. Rep. La Rice. Exp. Stn. 69:196-232.

Spence, C., Alff, E., Johnson, C., Ramos, C., Donofrio, N., Sundaresan, V., and Bais, H. 2014. Natural rice rhizospheric microbes suppress rice blast infections. BMC Plant Biol. 14:130.

Tan, Y. P., Crous, P. W., and Shivas, R. G. 2018. Cryptic species of Curvularia in the culture collection of the Queensland Plant Pathology Herbarium. MycoKeys 35:1-25.

Veerappan, V., Rangnathan, U., and Mannar, J. 2019. Effect of organic foliar spray with pulse sprout extract on seed yield and quality of rice (Oryza sativa). J. Plant Nutr. 42:900-914.

Wang, G. Z., Jiang, X. L., Sha, Y. X., Yoshihiro, O., and Guo, D. B. 2009. Study of fungi causing blight of rice seedlings on dry seedbed in Ningxia. Acta Agric. Boreali-Occidentalis Sin. 18:184-187.

Wang, M., Wei, P., Cao, M., Zhu, L., and Lu, Y. 2016. First report of rice seedling blight caused by Burkholderia plantarii in North and Southeast China. Plant Dis. 100:645.

Wang, S., Liu, X. D., Yang, H., Sun, B. X., and Liao, J. K. 2011. Control efficiency of 7 fungicides to rice seedling blight. Agrochemicals 50:380-381.

Wang, S., Sun, L., Li, W. Q., Liu, J. X., Li, Y. G., and Wei, D. 2019. First report of seedling blight caused by Fusarium redolens on rice in Northeast China. Plant Dis. 103:1418.

Wei, S. J., Ni, G. R., and Pan, X. H. 2014. Research progress in biological control of rice fungal disease. Jiangxi Sci. 32:123-129.

White, T. J., Bruns, T., Lee, S., and Taylor, J. W. 1990. Amplification and direct sequencing of fungal ribosomal RNA genes for phylogenetics. Pages 315-322 in: PCR Protocols: A Guide to Methods and Applications. Academic Press, New York, NY.

Whithey, N. G. 1982. Effect of treatment on rice seedling emergence. Fungi Nematie 37:169-170.

Yin, J., Jackson, K. L., Candole, B. L., Csinos, A. S., and Ji, P. 2012. Aggressiveness and diversity of Phytophthora capsici on vegetable crops in Georgia. Ann. Appl. Biol. 160:191-200.

Yoneyama, K., Kono, Y., Yamaguchi, I., Horikoshi, M., and Hirooka, T. 1998. Toxoflavin is an essential factor for virulence of Burkholderia glumae causing rice seedling rot disease. Ann. Phytopathol. Soc. Jpn. 64:91-96.

Zhao, F. Z., Xu, Y. N., Zhi, W. Y., and Claude, A. 2001. Differentiation of monospore cultures within a isolate of Fusarium oxysporum vasinfectum. J. Northwest Sci. Tech. Univ. Agric. For. 3:101-103. 